\title{
Child physical abuse in Bahrain: a 10-year study, 2000-2009
}

\author{
F. Al-Mahroos ${ }^{1,2}$ and E. Al-Amer
}

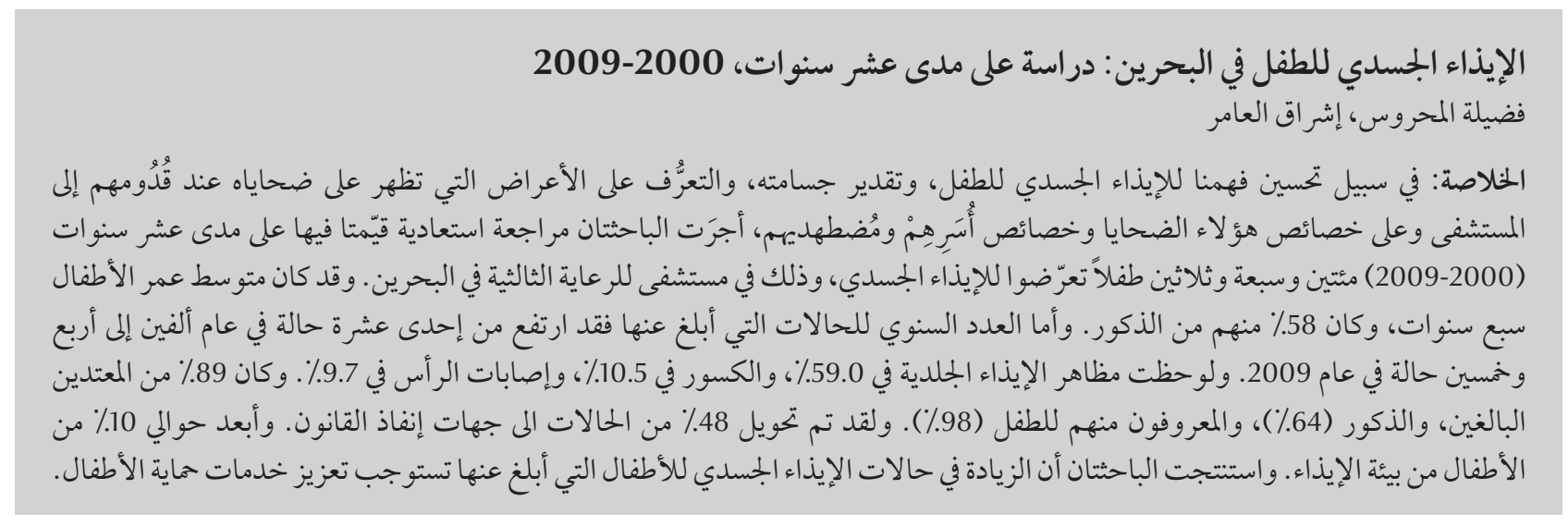

ABSTRACT To improve the understanding of child physical abuse, assess its magnitude, and identify the presentations and the characteristics of the victims, their families and the offenders, we carried out a retrospective review of 237 child physical abuse cases evaluated over 10 years (2000-2009) in a tertiary hospital in Bahrain. Mean age of the children was 7 years, $58 \%$ were males. The annual number of reported cases increased from 11 in 2000 to 54 in 2009. Skin manifestations were seen in $59.0 \%$, fractures in $10.5 \%$ and head injuries in $9.7 \%$. The perpetrators were adults (89\%), males (64\%) and known to the child (98\%). Referral to law enforcement was made in $48 \%$ of the cases. About $10 \%$ of the children were removed from the abusive environment. The increase in reported cases of child physical abuse calls for strengthening of child protection services.

\section{Violence physique infligée à l'enfant à Bahreïn : une étude sur 10 ans, 2000-2009}

RÉSUMÉ Pour accroître les connaissances sur la violence physique infligée à l'enfant, évaluer l'ampleur du phénomène, relever les présentations des victimes et les caractéristiques de ces dernières ainsi que celles de leur famille et des agresseurs, nous avons mené un examen rétrospectif de 237 cas de violence physique infligés à l'enfant, évalués sur dix ans (2000-2009) dans un hôpital de soins tertiaires à Bahreïn. L'âge moyen des enfants était sept ans, et $58 \%$ étaient de sexe masculin. Le nombre annuel de cas notifiés est passé de 11 en 2000 à 54 en 2009. Des manifestations cutanées ont été observées dans 59,0 \% des cas, des fractures dans 10,5\% des cas et des blessures à la tête dans 9,7\%. Les agresseurs étaient des adultes (89\%), de sexe masculin (64\%) et étaient connus de l'enfant (98\%). La police a été contactée dans $48 \%$ des cas. Environ $10 \%$ des enfants ont été soustraits de l'environnement violent où ils vivaient. L'augmentation des cas notifiés de violence physique infligée à l'enfant appelle un renforcement des services de protection en la matière.

'Sulmaniya Medical Complex, Ministry of Health, Manama, Bahrain (Correspondence to F. Al-Mahroos: fadheela@batelco.com.bh). ${ }^{2}$ College of Medicine and Medical Sciences, Arabian Gulf University, Manama, Bahrain.

Received: 25/08/10; accepted: 10/11/10 


\section{Introduction}

Child abuse and neglect (CAN) is a universal problem. The United Nations (UN) Secretary General's 2006 study on violence against children uncovered the magnitude of child maltreatment and the gross violation of children's rights across the globe [1]. Physical violence as defined by the United Nations study is "the intentional use of physical force against a child that either results in or has a high likelihood of resulting in harm to the child's health, survival, development or dignity" [1].

CAN is a major public health and social problem with devastating short and long-term consequences. Most children will have minor injuries but many might also have serious and lifethreatening conditions and some may even die. Long-term consequences of CAN may manifest as mental diseases such as depression and psychosis or physical illnesses such as diabetes mellitus, heart disease and cancer, which can manifest 50 years after the occurrence of abuse [2].

A study in the United States of America (USA) showed that nearly 3 million children experienced CAN as defined by the Endangerment Standard Definition of maltreatment [3]. Over half of these children were physically abused (57\%), more than a third (36\%) were emotionally abused and around a fifth (22\%) were sexually abused. An international collaborative study documented mothers' use of harsh or moderate forms of physical punishments by $4 \%$ of American women, $4 \%$ of Chileans, $21 \%$ of Filipinos, 26\% of Egyptians and 36\% of Indians [4]. It clearly shows that the rate of physical abuse is over 6 times greater in Egypt and 9 times greater in India than in the USA and Chile. Another study of abuse among 555 adolescent students in Beni Suef, Egypt, documented an overall abuse prevalence of $36.6 \%$ [5]. A cross-sectional study of schoolchildren in Alexandria, Egypt, revealed that more than a third were disciplined physically in the form of beating; a few were also burned or tied up [6].

In a study that provided an overview of the problem and patterns of child abuse and neglect in the 7 countries of the Arabian Peninsula, CAN was documented in Bahrain, Saudi Arabia, Kuwait, Oman and Yemen [7]. A more recent study conducted in Saudi Arabia from 2000 to 2008 reported 133 cases of CAN [8]. A retrospective study on a random sample of 1897 female university students in Jeddah reported exposure to physical and emotional child abuse by $45.1 \%$ and $50.6 \%$ of students respectively, and $2.9 \%$ reported exposure to forced contact sexual assault [9].

Further evidence comes from a survey of 117 paediatricians in Kuwait in which 50\% reported having encountered at least 1 case of abuse and up to 3 cases of neglect in the preceding year [10]. Physical punishment as a means of child discipline was supported by $86 \%$ of parents in another Kuwaiti survey [11].

In Bahrain, in a study conducted from 1991 to 2001, 60 children were seen in Sulmaniya Medical Complex with the diagnosis of child physical abuse. The most common manifestations were bruises in $45 \%$ and burns in $27 \%$; fractures were identified in $25 \%$ and head injuries in 19\%; 3 cases had abdominal injuries and 4 patients died [12]. Another study in Bahrain documented the widespread use of corporal punishment of girls at schools and homes [13].

The aforementioned research findings about CAN dispel the myth that child abuse is rare in our region. Furthermore, it uncovers the limited information known about the phenomenon of CAN and the gaps in our knowledge. This study is an attempt to fill some of the gaps and to effectively address the problem. In addition, our findings may have implications for the health of the population and the health system policy in Bahrain. The results are expected to potentially contribute to decision-making related to health care, social policy and legal reforms related to child protection

The general objective of this study was to improve the understanding of the phenomenon of child physical abuse in Bahrain. Specific objectives were to assess the magnitude of child physical abuse and to identify the presentations, family characteristics, and profiles of the abused and the offenders and identify the various forms of interventions.

\section{Methods}

Sulmaniya Medical Complex is the main secondary and tertiary care general hospital in Bahrain with about 1000 beds, of which 135 are paediatric beds. The Child Protection Unit at the hospital is run by a multidisciplinary team providing full assessment and treatment for all cases of CAN referred to the hospital. The team includes paediatricians, child psychiatrists, social workers and nurses.

We carried out this descriptive, retrospective review of the Child Protection Unit medical records of child physical abuse cases evaluated over the 10 years from January 2000 to December 2009 .

The operational definition of child physical abuse adopted in the current study was "child abuse that results in physical injuries, including fracture, burns, bruises, welts, cuts, and internal injuries. It also includes shaking, deliberate poisoning, suffocation, drowning, and "fictitious disorders by proxy" [14].

Data collection was done by the 2 investigators and involved reviewing all patients' files, recording the required data and coding it carefully. Data management and analysis was done using SPSS, version 17 for Windows. The coded data were entered by 2 data entry specialists. Data were checked for accuracy and errors of coding by the 
data entry specialists and the authors independently. Data were inspected carefully and frequency distribution done for all variables; any odd codes or items were double checked and corrected or deleted accordingly. This process extended from July 2009 to June 2010.

The study included all children from birth to below 18 years of age who were evaluated by the Child Protection Unit for physical abuse, with or without sexual abuse. Cases with sexual abuse only were excluded because the focus of this report was child physical abuse. Cases that had signs and symptoms indicative of diseases mimicking child abuse or incidental injuries were excluded.

The key elements included were the demographic data, family, child and perpetrators characteristics, the nature of injuries to the child, and interventions. The nature offather's job was used as a general measure of socioeconomic status. Highly paid jobs were managers and professionals such as doctors, engineers and lawyers. Moderately paid jobs included teachers and supervisors. Low-paid jobs were labouring and other blue collar jobs.

In this review of medical records, the identity of the patients was kept strictly confidential. Institutional scientific and ethical clearance for this research proposal was obtained from the Health Research Committee at Sulmaniya Medical Complex. This study was not funded by any funding agency and there was no conflict of interest to be declared by the authors.

\section{Results}

The records over a 10 -year period, January 2000-December 2009, were reviewed. The total number of children was 237, 152 (64\%) of them had physical abuse only and 85 (36\%) were subjected to both physical and sexual abuse. Abuse was classed as certain in $204(86 \%)$, very suspicious in 23 $(10 \%)$ and suspicious in $10(4 \%)$ of the cases. Unsubstantiated cases were not included and their details were unknown because they were not included in the child abuse register. Details of the abused children's demographics are presented in Table 1 . The vast majority (88\%) of the cases were in children aged 12 years or under and some $28 \%$ were preschoolers.

Over the 10 years there was a clear increase in the number of cases, in particular after 2005, from 11 cases per year in 2000 to 54 in 2009 (Table 2). Child physical abuse occurred in all areas of Bahrain; however, in order of frequency, Manama, Muharraq, Northern area and Hamad Town had higher numbers than other regions and this corresponds with the higher population density in those areas [15].

Sources of referrals are presented in Table 3. Most of the referrals came from other departments at SMC. It is noticeable that referrals from schools were very small, only $3 \%$. This is questionable taking in consideration that almost $100 \%$ of children in the community go through the school system and spend 6-8 hours daily.

Skin manifestations were the most frequent presentation of child physical abuse (59.0\%), followed by swellings

\begin{tabular}{lcc}
\hline $\begin{array}{l}\text { Table } 1 \text { Sociodemographic characteristics of the } 237 \text { abused children in Bahrain, } \\
\text { 2000-2009 }\end{array}$ & No. \\
Characteristic & 137 & 58 \\
Sex & 100 & 42 \\
$\quad$ Male & & \\
$\quad$ Female & 204 & 86 \\
Nationality & 33 & 14 \\
Bahraini & & \\
Non-Bahraini & 64 & 28 \\
School and age (years) & 15 & 7 \\
Preschool < 3 & 121 & 53 \\
Kindergarten 3-< 6 & 25 & 11 \\
Primary school 6-12 & 3 & 1 \\
Intermediate 13-15 & 9 & 4 \\
$\quad$ Secondary 16-18 & & \\
$\quad$ Unknown & & \\
\hline
\end{tabular}

Mean age was 7 years (range 1 day-17 years).

\begin{tabular}{lcc}
\hline \multicolumn{3}{l}{$\begin{array}{l}\text { Table } 2 \text { Prevalence of child physical abuse documented at Sulmaniya Medical } \\
\text { Complex, Manama, Bahrain, by year }\end{array}$} \\
\hline Year & No. & $\%$ \\
2000 & 11 & 4.6 \\
2001 & 19 & 8.0 \\
2002 & 16 & 6.8 \\
2003 & 14 & 5.9 \\
2004 & 8 & 3.4 \\
2005 & 11 & 4.6 \\
2006 & 34 & 14.3 \\
2007 & 41 & 17.3 \\
2008 & 29 & 12.2 \\
2009 & 54 & 22.8 \\
Total & 237 & 100.0 \\
\hline
\end{tabular}




\begin{tabular}{lcc}
\hline Table 3 Sources of referral to the Child Protection Unit of Sulmaniya Medical \\
Complex of the 237 abused children in Bahrain, 2000-2009 \\
\begin{tabular}{lcc} 
Source & No. & $\%$ \\
Other departments in Sulmaniya Medical & 97 & 41 \\
$\quad$ Complex & 33 & 14 \\
Local health centre & 32 & 13 \\
Centre for child protection & 21 & 9 \\
Police & 4 & 2 \\
Public prosecutor & 7 & 3 \\
School & 3 & 1 \\
Private clinic or hospital & & 2 \\
\hline
\end{tabular}
\end{tabular}

\begin{tabular}{lcc}
\hline \multicolumn{3}{l}{ Table 4 Child physical abuse presentation in $\mathbf{2 3 7}$ abused children in Bahrain, } \\
$\begin{array}{l}\text { 2000-2009 } \\
\text { Presentation }\end{array}$ & No. & $\%$ \\
Bruises & 93 & 39.0 \\
Swelling & 45 & 19.0 \\
Burn & 31 & 13.0 \\
Fractures & 25 & 10.5 \\
Head injury & 23 & 9.7 \\
Cuts & 17 & 7.2 \\
Skull fracture & 11 & 4.6 \\
Abdominal injury & 3 & 1.3 \\
\hline
\end{tabular}

ancluded in head injury.

\begin{tabular}{|c|c|c|}
\hline Characteristic & No. & $\%$ \\
\hline \multicolumn{3}{|l|}{ Socioeconomic status ${ }^{a}$} \\
\hline Low & 124 & 53.0 \\
\hline Middle & 71 & 31.0 \\
\hline High & 23 & 10.0 \\
\hline Parents divorced & 63 & 27.0 \\
\hline \multicolumn{3}{|l|}{ Father's wives } \\
\hline 1 & 181 & 80.0 \\
\hline$\geq 2$ & 17 & 7.0 \\
\hline Father unemployed & 27 & 12.0 \\
\hline \multicolumn{3}{|l|}{ Alcohol abuse } \\
\hline Father & 51 & 21.0 \\
\hline Mother & 9 & 3.8 \\
\hline \multicolumn{3}{|l|}{ Drug abuse } \\
\hline Father & 21 & 8.9 \\
\hline Mother & 6 & 2.5 \\
\hline \multicolumn{3}{|l|}{ Criminal record } \\
\hline Father & 39 & 16.5 \\
\hline Mother & 9 & 3.8 \\
\hline
\end{tabular}

${ }^{a}$ Some data are missing.
(19.0\%) fractures $(10.5 \%)$ and head injuries (9.7\%) (Table 4). Four fatal cases occurred in infants under 1 year of age who presented with apnoea, seizures and coma, with head injury as the cause of death.

Family characteristics are shown on Table 5. The rate of illiteracy among fathers and mothers were $16.0 \%$ and $11.7 \%$ respectively. The average number of children was 4 per family, with a range of $1-16$.

Perpetrators came from all socioeconomic and education levels, and no specific pattern emerges (Table 6).

Fathers were the most common physical abusers (36\%), followed by mothers (28\%) (Table 7). Overall, 193 (98\%) of the abusers were well known to the child.

Children received medical care in $196(83 \%)$ cases and surgical treatment in 23 (10\%). Additionally, 171 (72\%) were referred for psychiatric assessment/treatment and 204 (86\%) for social intervention. Social intervention starts with full assessment of socioeconomic status and provides support and guidance in child rearing, family counselling and the referral to various ministries for financial and housing advice, child placement and legal support.

Referral to the police and public prosecution was done in 114 (48\%) and 66 (28\%) of the cases respectively; 30 (13\%) of these reached the court and $25(10.5 \%)$ were removed from the abusive environment, either by removing the child from the family or by granting custody to the non-abusive parent or to a grandmother by public prosecutors or a court order.

\section{Discussion}

This study revealed a clear increase in the number of reported child physical abuse cases over the 10 years covered in the study. A similar trend of increase in the number of reported cases of CAN 


\begin{tabular}{|c|c|c|}
\hline \multicolumn{3}{|c|}{$\begin{array}{l}\text { Table } 6 \text { Characteristics of the offenders in the cases of } 237 \text { abused children in } \\
\text { Bahrain, 2000-2009 }\end{array}$} \\
\hline Characteristic & No. & $\%$ \\
\hline \multicolumn{3}{|l|}{ Nationality } \\
\hline Bahraini & 104 & 44 \\
\hline Non-Bahraini & 36 & 15 \\
\hline Unknown & 97 & 41 \\
\hline \multicolumn{3}{|l|}{ Sex } \\
\hline Male & 139 & 64 \\
\hline Female & 78 & 36 \\
\hline \multicolumn{3}{|l|}{ Age } \\
\hline Adult & 183 & 89 \\
\hline Adolescent & 20 & 10 \\
\hline Other child & 3 & 1.5 \\
\hline \multicolumn{3}{|l|}{ Education } \\
\hline Illiterate & 16 & 10 \\
\hline Primary education & 64 & 41 \\
\hline Secondary education & 43 & 27 \\
\hline College graduate & 32 & 20 \\
\hline Drop-out & 3 & 2 \\
\hline Unknown & 79 & 33 \\
\hline Alcohol abuse & 37 & 16 \\
\hline Drug abuse & 17 & 7 \\
\hline Criminal record & 47 & 20 \\
\hline
\end{tabular}

was documented in a similar previous study in Bahrain [12]. This increase may reflect a genuine rise in the incidence of child physical abuse or it may reflect an improvement in recognition

and referral of cases by professionals, which can be attributed to the upsurge in national and international interest and professional educational activities about CAN. Any such improvement

\begin{tabular}{lcc}
\hline $\begin{array}{l}\text { Table 7 Offender's relationship to the child in the cases of } \mathbf{2 3 7} \text { abused children in } \\
\text { Bahrain, 2000-2009 }\end{array}$ & No. \\
\hline Relationship & 70 & $\%$ \\
Father & 54 & 28 \\
Mother & 12 & 6 \\
Teacher & 11 & 6 \\
Housemaid/babysitter & 10 & 5 \\
Other relative & 9 & 5 \\
Step-father & 8 & 4 \\
Step-mother & 7 & 4 \\
Sibling & 4 & 2 \\
Stranger & 3 & 1.5 \\
School friend & 2 & 1 \\
Neighbour & 2 & 1 \\
Family friend & 1 & 0.5 \\
School employee & 193 & 100 \\
Total &
\end{tabular}

In 44 cases, the relationship was unknown or unrecorded. in reporting may also be due to the increase in public consciousness as a result of increasing media reporting and awareness campaigns.

A similar trend was documented in a study done in Saudi Arabia from 2000 to 2008 in which the number of referred CAN cases increased 10-fold [8]. Internationally, the World Perspectives on Child Abuse report indicated that two-thirds of the responding professionals from 58 countries around the globe reported that the number of child abuse cases has increased in their countries [16].

Similarly, in the USA, there was an unrelenting rise in the incidence of child maltreatment. However, the 2005 national incidence study of CAN reported for the first time a reversal in this trend [3].

Males represented 58\% and females $42 \%$ of the children in this study. This over-representation of males is consistent with the previous report about child physical abuse in Bahrain in which $63 \%$ were males and $37 \%$ were females [12]. However, this is a departure from international data which indicate that females were the main victims in CAN $[1,3]$ The exact cause is unclear; some cultural factors may play a role. Further study is needed to understand this phenomenon.

Furthermore, a global perspective on corporal punishment and gender is highlighted recently by a study based on interviews conducted with 1398 mothers, 1146 fathers, and 1417 children (age range $7-10$ years) in China, Colombia, Italy, Jordan, Kenya, the Philippines, Sweden, Thailand, and the United States. Across the entire sample, 54\% of girls and $58 \%$ of boys had experienced mild corporal punishment, and 13\% of girls and $14 \%$ of boys had experienced severe corporal punishment Overall, boys were more frequently punished physically than were girls. This is compatible with the findings in our study [17].

The main victims of child physical abuse in our study were children 6-12 
years followed by children under 3 years, diminishing with increasing age. This is compatible with the observation in most international studies in which younger children are at more risk of all forms of CAN. Preschoolers, however, were fewer than primary school children in this study. This might reflect a genuine low risk of abuse or it may be because the very young are less verbal and/or less likely to be visible to professionals or adults outside the family circle. This finding means that focusing preventive measures on preschoolers and primary school children and their families would address over $80 \%$ of atrisk children.

Most of the referrals in this study came from governmental medical facilities. However, it is noticeable that referral from schools was only $3 \%$ and from private clinics and hospitals only $1 \%$. This is atypical because schools are expected to be the main source of referral due to the intensive daily contact with almost all children, especially in Bahrain where the student enrolment rate is over $100 \%$ annually [18]. In contrast, in the USA school staff predominated as a source of recognition of maltreated children, recognizing $52 \%$ of the children who suffered harm standard maltreatment [3]. It is not clear if this study finding of low referral is due to the lack of recognition of child physical abuse by school staff and private sector medical personnel or to unwillingness to refer cases or to both factors. None-the-less, this finding clearly indicates that the vast majority of child physical abuse cases is not addressed and emphasizes the need for a mandatory reporting law.

It is well documented in studies of child physical abuse around the world that skin manifestations were the most frequent presentation. The rate of fractures in this study was $10.5 \%$ and head injury was $9.7 \%$. This is lower than the rate documented in the previous study ( $25 \%$ and $19 \%$ respectively) [12]. In comparison, a retrospective study from Egypt evaluated 41 cases of child deaths from family violence and found that the highest incidence occurred in those aged 3-6 years (39.0\%) [19]

The parents of $27 \%$ of the children were divorced; this is much higher than the reported rate of divorce (15\%) among the general population in Bahrain [18]. Unemployment rate among the fathers of abused children was $12 \%$, which is more than double the official unemployment rate estimate among the general population of Bahrain [18]. Low socioeconomic status is overrepresented in this study sample (53\%), however, all socioeconomic classes were represented and it is probably safe to say that although lower socioeconomic class might put children at greater risk of CAN, higher socioeconomic class does not guarantee the child's safety. This highlights the multifactorial risk factors of CAN.

The rate of illiteracy among the fathers $(16 \%)$ is more than double the rate of adult illiteracy among the general population in Bahrain, which is $7.5 \%$ for males over 15 years of age [15]. However, mother's illiteracy rate was $11.7 \%$, which is actually lower than the $17 \%$ rate among the general females population over 15 years of age [15]. It is also lower than the fathers of the children in the study sample. However, the general population illiteracy rate was obtained from the last census, 2001, and most likely the rates have changed since then.

Substance abuse and criminal records were reported among the fathers and mothers of this study sample. Although no data available about the general population for comparison, these rates might underestimate the size of the problem because the study depended on the parents' report.

Most of the known physical abusers were male adults. The predominance of male perpetrators is well documented in CAN studies throughout the world, especially where patriarchal attitudes prevail [1]. In the USA, male offenders were more frequent than females ( $62 \%$ versus $41 \%$ ) and similar to this study, the proportion of male perpetrators was even greater in the child sexual abuse category ( $87 \%$ males versus $11 \%$ females) [3]. Similarly, in the study from Egypt the majority of perpetrators of fatal cases were males (75.62\%) [19]. Therefore, including males as a target group in preventive measures is essential in the quest to combat CAN.

We found that biological parents were responsible for $64 \%$ of child physical abuse, and overall $98 \%$ of the abusers were well known to the child and supposed to be a source of trust and security rather than intimidation and threat. Similarly, a study of female university students in Jeddah revealed that parents and siblings were the main perpetrators of both physical and emotional abuse [9] Likewise, in a USA study biological parents were responsible for $81 \%$ of the maltreatment [3].

Perpetrators in this study came from various educational backgrounds and from all socioeconomic classes, once again emphasizing that there is no specific distinguishing attribute or profile for offenders: they come from all walks of life. In this study, $10.5 \%$ of the children were removed from the abusive environment. In comparison, in the 2000 study [12] none of the abused children were removed from the family.

Overall, there has been an improvement in responding to CAN in Bahrain; this may be attributed to better communication between professionals from different sectors and disciplines and to the existence of intervention guidelines and the establishment in May 2007 of the Child Protection Centre, a multidisciplinary facility under the auspices of the Ministry of Social Development. The centre provides social, psychological and medical assessment and treatment for children. In addition, female police officers are available to interview the child in the presence of the social worker in the centre. 
Despite the improvement in response to CAN in Bahrain and the availability of basic child protection services, there is still a long way to go. Our study is most likely to have revealed only the tip of the iceberg and there are many more unrecognized victims. A negligible number of cases were referred from schools; cases reaching court are limited, and the rate of indictment is low. To protect children, as a minimum, there is a need to meet the commitment to children as stipulated in the UN Convention on the Rights of the Child [20] and treat children truly as rights holders entitled to protection not less than, and ideally more than, adults.

To sum up, this study revealed a steady increase in reported cases of child physical abuse which calls for strengthening of child protection services. To reduce the number of missed cases, there is a need for mandatory reporting law. There is a need for emphases on multidisciplinary team work. Further studies based on general population surveys are needed to more accurately identify the scope of CAN, risk factors and the protective factors in the family and community.

\section{Study limitations}

Using the father's job as a convenient indicator of socioeconomic status limits the validity of this measurement. The study addressed cases that had been reported to Child Protection Unit in a medical facility; therefore, it is most likely to underestimate the true incidence of child maltreatment. In addition, it overestimates the severity of CAN because cases were from

\section{References}

1. Pinheiro PS. World report on violence against children. United Nations Secretary-General's study on violence against children. Geneva, ATAR Roto Presse SA, 2006.

2. Felitti VJ et al. Relationship of childhood abuse and household dysfunction to many of the leading causes of death in adults: the Adverse Childhood Experiences (ACE) Study. American Journal of Preventive Medicine, 1998, 14(4):245-258.

3. Sedlak AJ et al. Fourth National Incidence Study of Child Abuse and Neglect (NIS-4): Report to Congress. Washington, DC, US Department of Health and Human Services, Administration for Children and Families, 2010

4. World report on violence and health. Geneva, World Health Organization, 2002

5. Afifi ZE et al. Adolescent abuse in a community sample in Beni Suef, Egypt: prevalence and risk factors. Eastern Mediterranean Health Journal, 2003, 9(5-6):1003-1018.

6. Youssef RM, Attia MS, Kamel MI. Children experiencing violence. I: Parental use of corporal punishment. Child Abuse \& Neglect, 1998, 22(10):959-973.

7. Al-Mahroos FT. Child abuse and neglect in the Arab Peninsula. Saudi Medical Journal, 2007, 28(2):241-248.

8. Al Eissa M, Almuneef M. Child abuse and neglect in Saudi Arabia: journey of recognition to implementation of national prevention strategies. Child Abuse \& Neglect, 2010, 34(1):28-33.

9. Ibrahim NK et al. Prevalence, risk factors and outcome of childhood abuse reported by female university students in Jeddah. Journal of the Egyptian Public Health Association, 2008, 83(5-6):329-351.

10. Al-Moosa A et al. Pediatricians' knowledge, attitudes and experience regarding child maltreatment in Kuwait. Child Abuse \& Neglect, 2003, 27(10):1161-1178.
11. Qasem FS et al. Attitudes of Kuwaiti parents toward physical punishment of children. Child Abuse \& Neglect, 1998, 22(12):1189-1202.

12. Al-Mahroos F et al. Child abuse: Bahrain's experience. Child Abuse \& Neglect, 2005, 29 (2):187-193.

13. Al-Mahroos FT. Corporal punishment and psychological maltreatment of school girls in Bahrain. Bahrain Medical Bulletin, 1997, 19(3):70-73.

14. Child Protection Committee. Child Protection Plan. Bahrain, Ministry of Health, 1998.

15. Bahrain National Census (2001). Manama, Health Informatics Organization, 2001.

16. World Perspectives on Child Abuse, 8th ed. Hong Kong, International Society for the Prevention of Child Abuse and Neglect (ISPCAN), 2008.

17. Lansford JE et al. Corporal punishment of children in nine countries as a function of child gender and parent gender. International Journal of Pediatrics, 2010, 672780.

18. Bahrain in figures 2007-2008. Manama, Central Informatics Organization, 2009 (http://www.cio.gov.bh/cio_ara/English/Publications/Bahrain\%20in\%20Figure/BIF2007_2008. pdf, accessed 12 August 2010).

19. El-Hak SA, Ali MA, El-Atta HM. Child deaths from family vioAM lence in Dakahlia and Damiatta Governorates, Egypt. Journal of Forensic and Legal Medicine, 2009, 16(7):388-391.

20. United Nations Convention on the Rights of the Child. Geneva, UNHCR, 1989 (http://www2.ohchr.org/english/law/crc.htm, accessed 4 April 2012). 